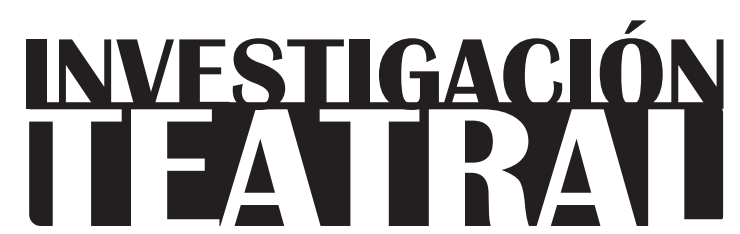

Revista de artes escénicas y performatividad

Vol. 10, Núm. 15

abril-septiembre 2019

Segunda época

ISSN impreso: 1665-8728

ISSN electrónico: 2594-0953

Universidad Veracruzana

Reseña:

\title{
La Muestra Estatal de Teatro de Chihuahua 2018: desmontajes y reseñas
}

\author{
Carlos Urani Montiel*
}

\footnotetext{
* Departamento de Humanidades, Universidad Autónoma de Ciudad Juárez, México.

e-mail: carlos.montiel@uacj.mx
}

Recibido: 11 de septiembre de 2018

Aceptado: 09 de enero de 2019 


\section{La Muestra Estatal de Teatro de Chihuahua 2018: desmontajes y reseñas} ace dos años y medio, un grupo de estudiantes y yo presentamos una iniciativa ante la comunidad artística y académica de Ciudad Juárez, Chihuahua: el Centro de Investigación y Documentación Dramática Norteatro. ${ }^{1}$ Nació por la necesidad de guardar y difundir la memoria del teatro escrito, producido y puesto en escena en el norte de México, en particular en nuestra localidad. Su portal (norteatro. com) sirve de archivo digital y plataforma para el estudio, discusión y enseñanza del arte dramático. El interés se concentra en la actividad escénica de una región que cuenta con una sólida tradición de dramaturgos, festivales, compañías e investigadores. Además de los contenidos que difundimos en internet y redes sociales -principalmente, reseñas de las puestas en escena-, interactuamos de forma directa con el público en varios escenarios y distintos momentos.

En el Festival Internacional del Drama Español Siglo de Oro, por ejemplo, antes de la función contextualizamos las obras que participan en este evento bifronterizo, el más antiguo dedicado al teatro clásico hispano. Acepté la invitación del municipio para ser juez en el 35 Festival de Teatro de la Ciudad, en julio de 2017; también entrevistamos -después del espectáculo- a los grupos artísticos que visitan la ciudad año con año en el Festival Internacional Teatro sin Fronteras, organizado por la compañía Telón de Arena. Recientemente, realizamos el Taller de Espectadores, un foro de convivencia y reflexión que sigue el modelo de la escuela fundada por Jorge Dubatti, en el que, a lo largo de 15

1 El colectivo se conforma por Amalia Rodríguez Isais, maestra en Estudios Literarios, así como por Karla Moreno Diego y Grecia Márquez García, licenciadas en Literatura. 
sesiones, compartimos experiencias y conocimiento con teatristas y gente siempre atenta a la cartelera local. Por último, la vinculación más importante -y que le da sentido al presente testimonio- fue la conseguida con la Secretaría de Cultura de Chihuahua para que Norteatro fuera parte activa, por segundo año consecutivo, de la Muestra Estatal de Teatro (MET).

En estas líneas pretendo realizar una revisión de la MET, a partir de una mirada crítica, asumida por el colectivo al que pertenezco. Así que, en un primer momento, reflexiono sobre la gestión en torno al diseño del programa, en donde se involucran cuestiones legales, de pertinencia y selección, previas a la inauguración, pero determinantes en el devenir de la MET. Posteriormente, desde la crítica teatral y como coordinador de Norteatro, recojo la experiencia del diálogo sostenido con las propuestas más interesantes: La luz de las ausencias, Apapacho, Por favor cierra la puerta, gracias y El caimán y los sapos. Las consideraciones finales sintetizan mis opiniones y sugieren recomendaciones en donde la labor de Norteatro busca consolidarse como un elemento constitutivo de futuras muestras.

Investigación, desmontaje y reseña crítica conforman las fases de un trabajo conjunto que atendió las nueve puestas en escena que participaron en la MET. Los desmontajes realizados frente al público, y con los miembros de cada compañía, fueron coordinados por los asistentes al Taller de Espectadores. Los desmontajes, opina Ileana Diéguez, aportan otros horizontes a quienes conciben "la teatralidad como un laboratorio para la configuración de los imaginarios sociales"; además del resultado, los teatristas comparten "procesos de búsqueda, investigación, entrenamiento y construcción, integrándolos en un evento artístico-pedagógico" (15-16). La asignación de las obras dependió del gusto y habilidades de los talleristas. El objetivo de la actividad se dirige hacia la exposición del trabajo previo de la puesta en escena: producción, propósito y limitaciones. En las entrevistas, investigación y creación dialogan a favor de la reflexión en torno al hecho teatral recién ocurrido.

\section{Gestión y curaduría}

Las Muestras Estatales de Teatro se han efectuado durante tres años continuos, gracias al impulso de un proyecto de alcance nacional de la Secretaría de Cultura en su nivel federal. Aunque la convocatoria es emitida por dicha institución -y se podría calificar de centralista-, los estados tienen la facultad de adecuarla a sus necesidades. Si, por un lado, las muestras contribuyen al fortalecimiento de la expresión dramática a través de una plataforma de exhibición de los grupos de cada entidad, por otro también debería 
existir un filtro - por medio de una curaduría cabal- que garantice que sean el receptáculo anual de lo más relevante de las escenas estatales. Ésa tendría que ser la consigna institucional. ${ }^{2}$ Reunir en un tiempo y espacio común "a la parte activa del teatro de todos los estados -opina Fernando de Ita- permite tener literalmente una visión individual y de conjunto del estado que guarda el teatro público por entidad, por región y a nivel nacional" (37).

En Chihuahua, esta iniciativa de difusión artística y congregación gremial celebró su emisión número 27, en 2018. En la pasada MET de Ciudad Juárez, 14 funciones, montadas por nueve compañías durante cuatro días, prometían un recorrido por las propuestas escénicas estatales. La dramaturga Maribel Carrasco, el gestor cultural y director Aristeo Mora, además del dramaturgo, director y ensayista Alberto Villarreal, conformaron el jurado, una tercia de buen nivel. Además de la exhibición, los montajes compitieron para llegar a la 39 Muestra Nacional de Teatro, celebrada en la Ciudad de México, en noviembre de 2018 -en donde Norteatro también se hizo presente, en la Muestra Crítica-, con una parada intermedia en la Muestra Regional de Teatro Noreste, en Tamaulipas.

Desde el primer día, me cuestioné sobre la impresión de los evaluadores ante la disparidad. ¿Pasmo, incredulidad, suspensión del juicio? Uno de ellos, Villarreal, afirma que "la naturaleza del teatro, en su accionar práctico y estético, es la desestabilización, sólo con esto se consigue vitalidad" (citado en Bujeiro, "El teatro como contrapeso" 92). El dictamen final se convirtió en intriga; no por la obra ganadora o la suplente, ya que la contienda recaía en dos o tres propuestas -aún menos cuando una quedó descalificada-, sino por los reconocimientos a director, escenografía, actores y dramaturgia. ¿De dónde escoger? Por fortuna, la deliberación no decepcionó. La premiación traía consigo apostillas y congojas para los organizadores. Los jueces, en aprecio a su tiempo y trayectoria, se desligaron de la planificación de la MET; incluso, informaron que, de las ocho carpetas participantes en la convocatoria - por ellos nunca consultadas-, fueron aceptadas todas, por lo que no hubo condiciones suficientes para deliberar sobre quiénes merecían reconocimiento individual. El escrutinio se hizo polvo y desierto.

Hubo grupos que decidieron no postularse. Me refiero a un par de casos que, aunque lejanos a las tablas, devinieron en la abstención. La comunidad artística estatal aún recuerda cuando, en la MET 2016, Hybris Teatro obtuvo el primer lugar con Lo que queda de

2 En su su reseña sobre la Muestra Nacional de Teatro 2017, celebrada en León, Guanajuato, Enrique Olmos de Ita dice que ésta funcionó "como un festival dado que la programación, desbalanceada en lo estético y geográfico, en realidad encarna las transitorias voluntades de un órgano colegiado (dirección artística), tal y como operan los festivales de artes escénicas comunes y corrientes, sin pretender una visión íntegra en excelencia o un recuento 'de lo mejor"' (párrafo 2). 
INVESTIGACIÓNTEATRAL

Vol. 10, Núm. 15

abril-septiembre 2019
La Muestra Estatal de Teatro

de Chihuahua 2018

Carlos Urani Montiel

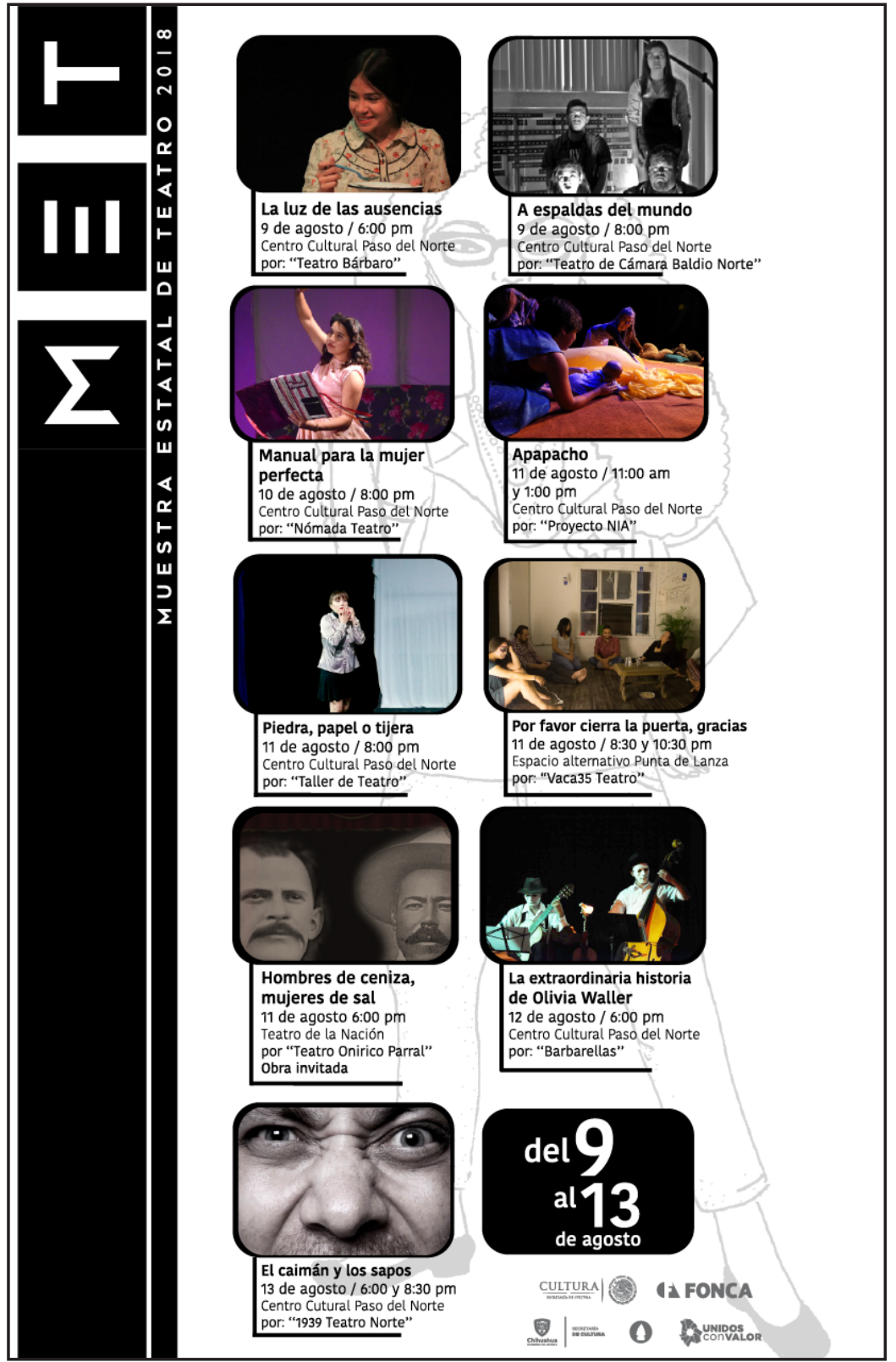

Programa de la MET.

Chihuahua, 2018.

Secretaría de Cultura.

nosotros, dirigida por Marco Martínez, pero - por cuestiones de derechos- la Coordinación de Artes Escénicas favoreció a la obra suplente, en vez de respaldar a los ganadores. La compañía, radicada en Ciudad Juárez, representa el paso a paso de un quehacer escénico original, independiente y profesional; a pesar de que su estreno fue extemporáneo, 
comprendo el desinterés. ${ }^{3}$ El otro caso es Telón de Arena, el grupo más longevo y numeroso en la entidad, que programa actividades culturales durante todo el año en su propio foro; como en la MET 2017 participó con cuatro obras y ahora la convocatoria señalaba que las "compañías y grupos teatrales podrían participar sólo con un montaje", su consejo artístico postuló tres (Río Ánimas, La señora Macbeth y Los de afuera), pero decidió no participar porque la cláusula sanciona la producción escénica en exceso. Con dichas omisiones, la MEт Chihuahua perdió su esencia. Estos hechos signan el trato de la institución con sus creadores y, así, el cometido de la calidad se puso en crisis en detrimento de toda línea curatorial.

\section{Teatro juvenil sin menores de edad}

La convocatoria restringe "montajes en cuyo reparto participen menores de edad"; la normativa también asienta que la "participación en la presente convocatoria implica la aceptación de las bases de la misma". Por ello, La luz de las ausencias, compuesta y dirigida por Saúl Enríquez, quedó descalificada. Esta obra es de Teatro Bárbaro, grupo artístico profesional de la capital del estado, que opera su propio foro y cuenta con el apoyo del programa México en Escena. La prohibición carece de sentido, pero no de claridad. ${ }^{4}$ Hace un año, la compañía presentó San Sipriano redentor y los Lágrima-team, de Raúl Valles, con un elenco incompleto, ya que el Niño Ladino era interpretado por un menor. Luis Bizarro, director de Teatro Bárbaro, desdeña las restricciones de carácter legal; incluso, confesó, durante la última premiación, que prefiere dar proyección y experiencia a su joven actriz Frida Serna -de 15 años-, quien dio vida al personaje de Tita en una obra "para toda la familia”, escrita especialmente para el grupo norteño.

En La luz de las ausencias, el peso de la marginalidad, la violencia en la sierra tarahumara, la discapacidad motriz del coprotagonista, León, así como el abandono de ambos padres, menguan ante una pregunta: “¿De qué estamos hechos?”. Tita y su hermano buscan

3 Las obras debían estrenarse entre el 1 de enero y el 13 de abril, fecha de lanzamiento de la convocatoria emitida por la Secretaría de Cultura del Estado de Chihuahua. Hybris Teatro estrenó Medio día, seguirá el mal tiempo, de Manuel Barragán, a finales de junio. En el Taller de Espectadores contamos con la presencia del director, Marco Martínez.

4 Concuerdo con Alejandra Serrano, quien ha documentado el teatro en los estados por más de una década, en su solicitud de revisión de las bases de las MET, sobre todo, para "evitar restricciones que son por demás absurdas" (37). Para más información, consultar su libro Teatro en los estados 2007-2017. 
averiguarlo. El motivo de la orfandad, recurrente en la dramaturgia de Saúl Enríquez, ${ }^{5}$ asola la vida de los protagonistas, quienes encuentran pequeños asideros en el quehacer cotidiano de la cocina o de la escuela rural. La sencillez del argumento, sostenida por un par de narradores siempre presentes, potencia varios planos expresivos, por medio de los cuales la puesta en escena se vincula con el espectador a través de la poesía, el olor, la música y el baile, además de una escenografía estática, pero multifuncional, sobre la que se aliñan metáforas de alto contenido emocional. ${ }^{6}$

Los narradores nos hablan desde un plano en el que ya todo ha ocurrido. Este orden cronológico-anacrónico (retrospectivo y a veces prospectivo) genera un distanciamiento frente a Tita y León, que delinea una atmósfera íntima para el relato oral. Sin embargo, esas figuras omniscientes que conocen motivaciones secretas y reflexiones privadas juegan otro papel. Además de enmarcar la fábula, pronto se corporizan e inciden en la escena, no de forma ilustrativa - es decir, no se hace lo que dicen-, sino que interactúan sutilmente con los personajes e incluso interpretan roles secundarios. Por otra parte, sus palabras no sólo narran sucesos espacio-temporales, sino que construyen imágenes poéticas a través del verso libre, paralelo al actuar de los hermanos: "Tierra adentro, / la sierra. / Adentro / se escuchan cantos. / Híkuri. / Medicina. / Silencio. / La obscuridad permite ver las estrellas como son, / más allá de su belleza; / León en medio de ella" (Enríquez). En un giro final y sorpresivo, los narradores abandonan la omnisciencia, develando su verdadero rol: testigos activos que desde el principio formaban parte del mundo de ficción, colaborando a que el saldo final en la historia sea positivo. ${ }^{7}$

El diseño horizontal de la escenografía se extiende de tal forma que acoge una estufa de carbón -recargada al extremo izquierdo-, y una amplia mesa de madera, en donde se sigue una receta -transmitida por la madre-, para preparar gorditas de trigo rellenas de chile con carne, sustento económico, a la vez que espiritual, de los consanguíneos. La preparación del alimento se convierte también en una secuencia que desprende aromas y colma

5 Así ocurre en Sie7e, de Nuca Merlot Teatro, y en La luz que causa una bala, obra ganadora de la MET Jalisco 2018. El fenómeno del abandono en la infancia se trata, según Enrique Olmos de Ita, "desde una perspectiva que no es popular, sino que alcanza profundidades oníricas y metáforas verdaderamente singulares" (párrafo 4).

6 A partir del desmontaje que realicé con la obra inaugural, redacté la reseña "Y ese es mi coraje", que se ocupa en exclusivo del concepto sonoro de La luz de las ausencias (2018).

7 La incertidumbre sobre la modalidad discursiva de la narración permite trasladar a la escena un perspectivismo múltiple, técnica que ha sido estudiada por José Sanchis Sinisterra, para quien las "afinidades y discrepancias entre el punto de vista del personaje narrador y el que la interacción dialogal proporciona al receptor constituyen una interesante fuente de ambigüedades y/o redundancias" (69). 
INVESTIGACIÓNTEATRAL

Revista de artes escénicas y performatividad

Vol. 10, Núm. 15

abril-septiembre 2019
La Muestra Estatal de Teatro

de Chihuahua 2018

Carlos Urani Montiel

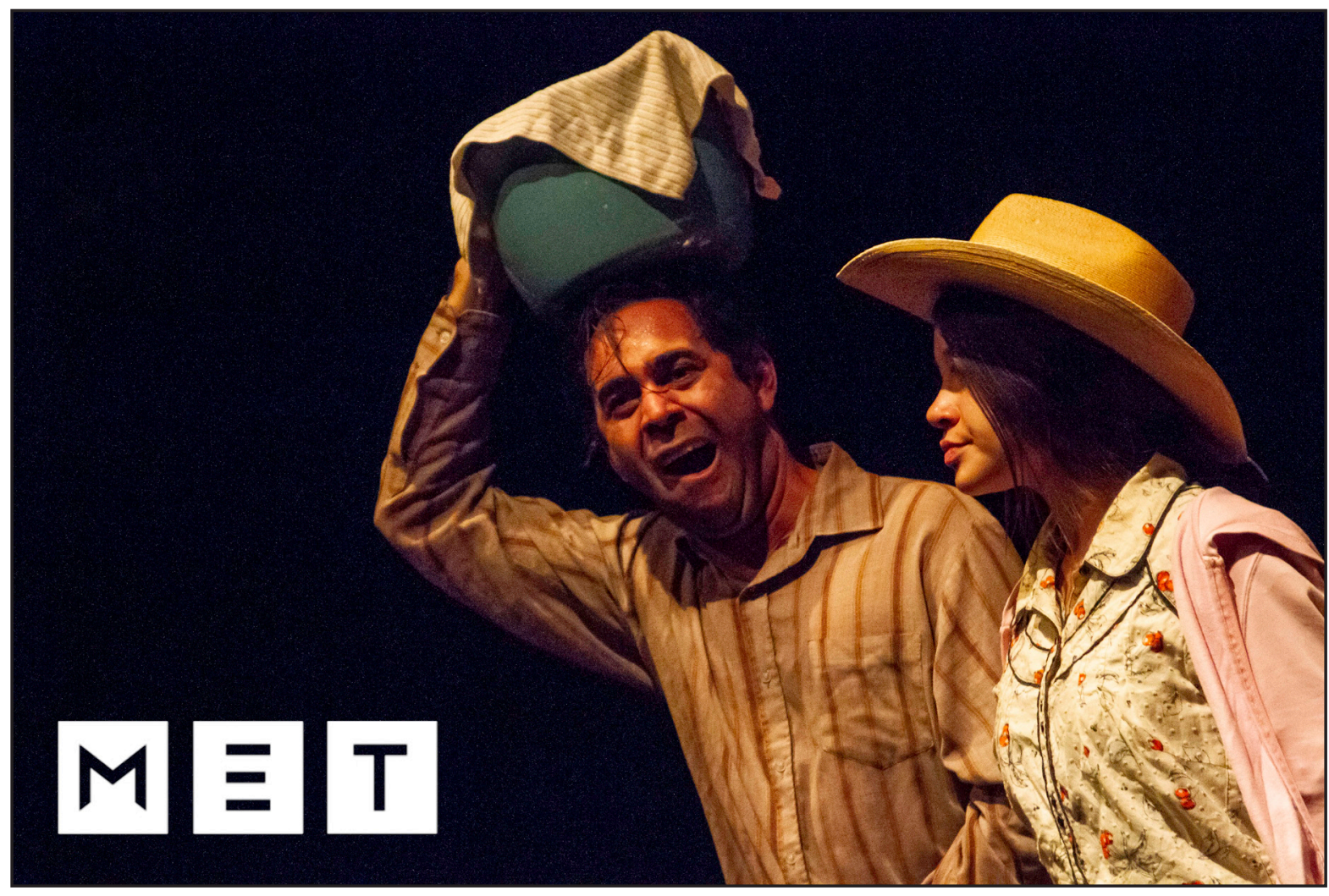

Teatro Bárbaro: La luz de las ausencias. 2018. Fotografía de Umberto Morales.

la sala de un calor hogareño al que tanto se aferran León y Tita. La luz de las ausencias conjuga el quehacer dramático de Teatro Bárbaro con la residencia de un director invitado; qué lástima que su emotividad y técnica no hayan sido recompensadas en la premiación, aunque sí en el teatro, que es lo que en verdad cuenta.

\section{Gatear en las tablas}

Desde que, en 2009, apareciera el libro Teatro para los primeros años, compilado por Wolfgang Schneider, las artes escénicas para la primera infancia - del nacimiento a los tres años- han cobrado auge y ya son una tendencia estable, por lo que cuentan con compañías y circuitos de representación especializados. En el teatro para bebés, los esfuerzos radican en la generación de vínculos comunicativos entre los artistas y los pequeños a partir de estrategias clave: escaso uso de lenguaje verbal, preeminencia de gestos y sonidos guturales, 
contacto visual, expresión y movimiento corporal como medios primarios de interacción. Estas habilidades se armonizan con el objetivo de provocar confianza, no sólo en los infantes, sino también en sus tutores, para que los primeros se involucren de lleno -con emoción, atención y cuerpo- en el espectáculo. ${ }^{8}$

Proyecto NIA, procedente de la ciudad de Chihuahua, participó en la MET con una doble función de Apapacho, dirigida por Nataly Muñoz Proo, quien desglosa su propuesta a partir del mismo título, como si fueran siglas: "Aprendizajes que Promueven Amor Para todos los que nos rodean. Abrazos del alma Con el cariño Hecho a la medida del Otro". El convivio inició en las afueras del Teatro Experimental Octavio Trías, en donde cuatro actores, caracterizados y a nivel de piso, dieron la bienvenida a los bebés, mientras que la directora, de pie, hacía lo propio con las mamás y los papás. Muchos asistían a este tipo de montajes por vez primera, así que había que aclarar las reglas del "juego escénico pre-conceptual" antes de ingresar a la sala: un cambiador inmediato a la entrada, un cartel con instrucciones que incentivaban el movimiento libre de los infantes: "Ellos deciden su participación, evitar forzar la interacción o limitarla".

Fernanda Avendaño, encargada del desmontaje, relata su experiencia: "Invitaban también a ejercer la lactancia materna con confianza y sin juicios, generando un espacio seguro para practicar la maternidad y paternidad de apego". El cuidado por el detalle promovió que el bebé explorara y disfrutara, "con su cuerpo, diversas formas sensitivas como el movimiento, los sonidos, los colores, la luz y las vibraciones" (Avendaño párrafo 2).

La expresión poética erigida sobre un escenario circular detona distintos estímulos sensoriales que atrapan al receptor. El papel que juega la audiencia traza una secuencia narrativa de afuera hacia adentro o viceversa porque, si bien existe cierta inercia argumental, resulta más potente la fuerza centrípeta que primero cautiva las miradas, pero que, conforme avanza el espectáculo y los histriones despliegan movimiento, atrae los cuerpos de los más ágiles y aventureros. El elenco entonces abandona el centro de la figura geométrica y rodea a unos nuevos personajes que recién experimentan las múltiples posibilidades de ser espectador.

Los jueces celebraron la propuesta de Proyecto NiA. De hecho, Maribel Carrasco escribe teatro infantil: Los cuervos no se peinan se escenifica por toda la República. Sin embargo, no entiendo por qué, si hubo un programa previo a la MET, compuesto por tres obras des-

8 Tras un compendio historiográfico, Evelyn Goldfinger concluye que "As the variety of theatre for babies productions illustrate, there is no single one way to design theatre for babies", ya que la audiencia responde de forma particular en cada parte del globo. No obstante, el proceso de producción sí presenta regularidades: "recalling the actors' personal experiences (as infants or with babies), watching baby videos, observing babies in relationship with their parents and/or conducting workshops with baby and caregiver audiences that are filmed and adults are asked for feedback" (296). 
tinadas a este público (MET Niños), no se incluyó ahí a Apapacho. Misterio insondable que seguro se reduce a una cuestión de papeleo o de cartera.

\section{Frontera creadora}

La condición fronteriza de Ciudad Juárez dicta acciones, rutinas y movimientos sociales propios de una vecindad, hecha unidad a fuerza de la interlocución entre distintas economías y modelos de habitar. Una madre, en el puente internacional, le desea suerte a su hija en su diario ir y venir al community college en El Chuco; una operadora apenas llega a tiempo a la parada de la ruta que la llevará al turno nocturno de la maquila; los locatarios, en las segundas de la Velarde, se gritan de una a otra acera; el mecánico halla en el tercer yonque la pieza automotriz que falta; los amigos se aposentan en esquinas, veredas o cruces en un habitual despliegue de historias singulares, que hacen del espacio fronterizo un escenario vital de intensas emociones. El teatro sabe recogerlas y las plasma en cuerpos que las revisten de añoranza.

Además de celebrar la nostalgia por una edad de oro bastante cercana, un eje de la obra Por favor cierra la puerta, gracias es la violencia como marca distintiva de la frontera; cada intérprete da cuenta de ella en sendos monólogos. En coproducción con el Laboratorio Escénico Teatro de Fronteras - perteneciente a Telón de Arena-, Vaca 35 de la Ciudad de México trajo a Juárez su proclama de “Teatro en grupo", cuyo sustento radica -como señala el director, Damián Cervantes- en la creación de espectáculos escénicos que dialoguen con el entorno y que propongan una reflexión profunda, tanto en actores como en quienes los miran a escasos centímetros. Por favor cierra la puerta, gracias encarna esta idea a partir de una dramaturgia colectiva próxima al biodrama que congregó las vivencias del elenco local.

Las historias individuales, llenas de soledad, melancolía, miedo y humor negro cartografiaron una metrópolis sitiada, pero con ganas de bailar y cantar. Antonio Rubio - quien dirigió el desmontaje- opina que la música de Juan Gabriel o de Los Silver "ayuda a crear esa atmósfera llena de nostalgia que se pretende evocar. En este caso, los actores no habitan estas espacialidades, sino que las exteriorizan por medio del recuerdo para combatir al horror" (párrafo 4). La obra se realiza en un espacio alternativo, donde la frontera se vuelve protagonista: la sala de un departamento céntrico en donde sólo caben 24 personas por función. Fue un reto trasladar el montaje, sin Ciudad Juárez como telón de fondo, a la Ciudad de México, en la Muestra Nacional de Teatro, en donde se presentó en la línea curatorial sobre testimonio, memoria e identidad.

Parece que el producto de toda residencia artística en la frontera debe girar en torno al (re)cuento de las víctimas. Cada vez que un grupo de creadores realiza una 
estancia en la ciudad, sin importar que haya juarenses involucrados, la violencia luce como tema, motivo o recurso retórico. ${ }^{9}$ Asumo la premisa de que el espíritu atiende experiencias límite con mayor presteza, respecto a actividades rutinarias; por tanto, estamos propensos a cargar de contenido emocional a los sitios donde esas vivencias ocurrieron y urdirlas en una secuencia narrativa que permite racionalizar y subsanar las secuelas. No obstante, y dando por hecho que en una reunión íntima de amigos no se relatan balaceras ni figuran anécdotas de encobijados, la violencia como eje expresivo es -y siempre será- una decisión, nunca una imposición, por más cruenta que sea nuestra realidad. Me parece que dicha resolución obedece a una tendencia institucional promovida por aparadores, premios y circuitos comerciales que socorren a creaciones que padecen -incluso enarbolan- el síntoma de la supervivencia. ¡Lo lograron! Salieron vivos de Juaritos y el mundo debe saberlo. Opino que existen otras formas discursivas que asumen la dignidad de la ciudadanía, aun y cuando recurran al retrato feral de nuestro norte. ${ }^{10}$

\section{Y la ganadora es...}

La MET bajó el telón con una doble función de El caimán y los sapos. La mancuerna entre la compañía 1939 Teatro Norte y la dramaturgia de Edeberto "Pilo" Galindo resulta tan natural en la frontera que sus producciones son garantía (Curva peligrosa, Acitrón de un fandango, Bubble Gum, En un tren militar, Filos y la futura De trapos corazón). Más allá del lazo familiar, existe una manera de componer que se expresa a través de un cauce en el que la sonoridad del diálogo, la materialización del entorno y el trazo escénico de cada secuencia potencian y enriquecen las palabras del dramaturgo, convirtiéndolas en acciones que apelan al espectador, al grado de que la respuesta emocional pareciera estar anticipada desde el texto dramático. Sin embargo, la escritura de "Pilo" Galindo, al carecer de acotaciones precisas, invita a que el ingenio del director - en este caso Abraxas Trías- configure un espacio propicio para que el auditorio sea uno con la trama.

9 Menciono tres ejemplos de distintas disciplinas: el cómic Viva la vida: los sueños de Ciudad Juárez, de Edmond Baudoin y Troub's (2011); la antología Road to Ciudad Juárez: crónicas y relatos de la frontera, compilada por Antonio Moreno (2014), y la puesta en escena Baños Roma, de la compañía Teatro Línea de Sombra (2013).

10 Como ejemplo, enumero otra terna: el poemario Juárez, tan lleno de sol y desolado, de Arminé Arjona (2004); Ciudad futuro, testimonio de Isaac Villa, "El Alas Blissett" (2012), y Fuenteovejuna, adaptación de Perla de la Rosa, escenificada por Telón de Arena (2017). 
Así ocurre en El caimán y los sapos, pieza documental que -tanto el título, como el dispositivo escénico y su adscripción a dicho género- involucra al receptor como comunidad o, en el peor de los casos, como cómplice. El docudrama extrae su asunto de un hecho real, lo que implica el embate del ámbito social dentro de la ficción. A mediados de 2013, Óscar Balderas publicó en el diario El Universal un artículo que combina la crónica periodística con el testimonio estremecedor de una joven víctima de la trata de blancas. "El Caimán, terror de trabajadoras sexuales en el DF" retrata la explotación de mujeres, muchas de ellas menores de edad, inmiscuidas en una red de corrupción donde operan varios agentes: captores, antros, "padrotes", poder judicial, altos funcionarios y aquellos quienes encubren el delito desde el silencio. La historia de Diana reconstruye la muerte de su "carnala" a manos de Ernesto, apodado "El Caimán": "El animal se comió a Andrea -recuerda su amiga y se estremece-. Te juro que esta historia es real; así castiga este desgraciado". El reportaje detalla el perfil del "sultán de Tenancingo", quien es una "maldad encarnada en un cuerpo moreno, fibroso [...] mirada demencial [...] habilidoso enamorador [...] no sólo es un proxeneta rico, sino uno amado, respetado, recolector de favores y sádico 'empresario"' (Balderas párrafo 23).

Si el documento periodístico constituye la base misma del texto dramático, su finalidad -noticia y denuncia- debía trasladarse a escena. El periodista asevera: "No es ficción, es un hombre real que [...] tiene víctimas en todo el país y que mata de miedo a las muchachas" (Balderas párrafo 14). La escenografía genera intimidad por lo limitado del rectángulo -tipo arena - cercado por 50 asistentes; también provoca fricción corporal, ya sea por la contigüidad entre las sillas o porque los actores transitan a través de corredores, detrás del público, y proyecta la sensación de encierro, obtenida con el plástico que nos confina a todos dentro de la caja negra. ${ }^{11}$ Yazmín Martínez, coordinadora del desmontaje, expresa su preocupación por "el hecho de no poder salir. En ese momento empezamos a sentir algo parecido al miedo de esas niñas, [...] una ansiedad ante la incertidumbre” (párrafo 2). El dispositivo escénico permite que la recreación de eventos se perciba tan próxima que el ejercicio de expectación se desestabilice, ya que no hay distancia entre el riesgo fingido y el desasosiego que incita. No sorprende, entonces, que al final, en pleno llanto, alguien se haya apresurado a abrazar a la actriz Laura Galindo, ni que una persona haya pensado que el desmontaje fue insensible por irrumpir el impacto de la obra, aun mucho después de los aplausos.

Criticar la propuesta de 1939 Teatro Norte parecería indolente, debido a lo duro del tema y a la conmoción que provoca. Uno podría argüir la relación directamente propor-

11 El capítulo "Público y expectación”, en El caimán y los sapos, de Edeberto "Pilo Galindo" estudia a detalle, y de forma comparativa, el montaje que aquí me ocupa, así como el producido por Teatro Bárbaro en la MET del año pasado (La puesta en escena y el espacio teatral 2017). 
INVESTIGACIÓNTEATRAL

Revista de artes escénicas y performatividad

Vol. 10, Núm. 15

abril-septiembre 2019
La Muestra Estatal de Teatro

de Chihuahua 2018

Carlos Urani Montiel

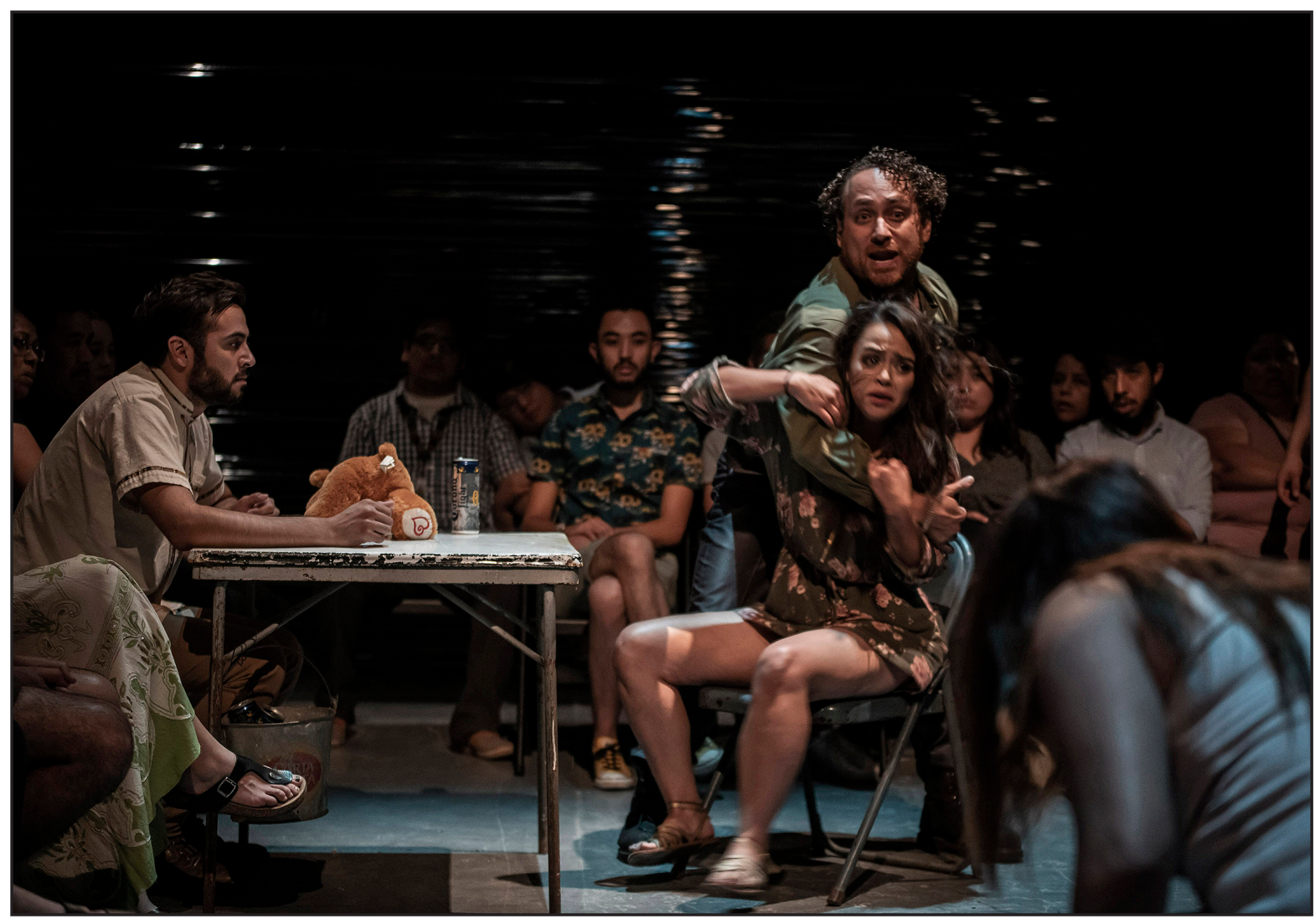

1939 Teatro Norte: El caimán y los sapos. 2018. Fotografía de Raúl Ramírez "Kigra”.

cional entre la violencia inherente al fenómeno y el furor con que se resuelven escenas cruciales; por ejemplo, cuando Andrea es sorprendida en la bañera y su amiga lucha porque no se la lleven. No obstante, el vals como metáfora de la tortura alega dicha apreciación. Por otra parte, aunque existe un personaje ajeno al tiempo de la fábula, es decir, el escritor que recoge el relato de la sobreviviente, su intervención no crea distancia, ya que durante la entrevista cede a la seducción de la informante y confiesa haber tenido tratos con una prostituta. Cuando esta figura, que esconde tras de sí la pluma del reportero o del dramaturgo, forma parte del problema, entonces el drama se concentra en la ficción y no en la reflexión. Un escritor en escena rompe la acción y apela a un cuerpo ajeno a los protagonistas, porque personifica la palabra, portavoz de una intención. Como esto no ocurre con el reportero de El caimán, el público se ve arrastrado por un torrente sensitivo que cancela su sentido crítico y demerita la reflexividad. Sin mediación o filtro, el observador olvida que la actriz representa, interpreta y cita. La crítica del teatro documental se expande cuando la fábula 
trastoca sólo a los personajes, al tiempo que reclama la interpretación del espectador ubicado afuera, aunque no ajeno ni inclemente, del universo representado.

\section{Consideraciones finales}

En la MEт 2018, celebrada en Ciudad Juárez, ${ }^{12}$ detecto dos rupturas: la de la normativa respecto a las condiciones locales y la de la Secretaría de Cultura, personificada por su titular Concepción Landa, en tanto que presume desinterés o desconoce las necesidades de los creadores. Ante ambas fracturas y el déficit a la respuesta de la convocatoria, las encargadas de Promoción y Difusión y de Desarrollo Cultural diseñaron un programa desequilibrado en contenido y pobre en calidad.

Frente a este panorama, ¿qué urge? ¿Cómo mejorar las siguientes emisiones? ¿Qué papel juega la crítica teatral? La cordialidad, el respeto y la transparencia me parecen clave para generar confianza y una línea horizontal de diálogo entre gestores y artistas. Un sitio web específico para la MET podría alojar y difundir la convocatoria -que cuesta tanto conseguir-, así como las carpetas de cada obra, los costos de realización y los tiempos de pago.

Lo primordial es una curaduría que dictamine las líneas generales del evento; sin ella, no hay esfuerzo ni inversión que valgan. Luz Emilia Aguilar Zinzer e Ilona Goyeneche consideran las MET "como un espacio para ejercitar la práctica curatorial -tan necesaria, pero aún tibiamente aceptada por el gremio, considerando ésta dentro de las posibilidades que permite el diseño mismo de las iniciativas estatales" (citado en Secretaría de Cultura del Estado de Jalisco 3).

En Chihuahua, en vez de nutrir el programa con los ocho postulantes, se pudo invitar a grupos profesionales para fortalecer el quehacer de agrupaciones emergentes en la entidad. Por otra parte, aunque con una incidencia plena, también es vital un marco jurídico que soporte la actividad de los teatristas. El problema se ha detectado año con año en el Encuentro de Creadores, pero las propuestas que de ahí emanan no trascienden en documentos oficiales. Urge revocar algunas cláusulas, como la referente a menores de edad, y apremiar que la convocatoria sea coherente con el teatro chihuahuense.

12 En el Encuentro de Creadores, celebrado en la ciudad de Chihuahua, a unos días de arrancar la Muestra, se enfatizó el adelanto en Jalisco respecto a los avances y fortalecimiento de su comunidad teatral. Norteatro viajó a Guadalajara para participar en el Laboratorio de desmontaje y de crítica abierta, coordinado por Luz Emilia Aguilar Zinzer e Ilona Goyeneche; esta sección también recoge lo vivido en la MET en tierras tapatías. Cabe mencionar que, de las 31 propuestas recibidas en Jalisco (de 50 cupos posibles), las curadoras seleccionaron 13 obras. 
Finalmente, ante la variedad de teatralidades, públicos y formatos, recomiendo rediseñar el formato de premiación. Los propios creadores, auxiliados por observadores externos -ya no como jurado-, pueden llegar a un consenso para designar la propuesta más representativa. A fin de cuentas, la MET es un encuentro que materializa, en una semana, el trabajo anual de todo un gremio. Procuremos este espacio en donde creadores, críticos, gestores y público celebran y atienden sus artes escénicas.

Cuando la institución administra recursos, también establece valores de legitimación. Por ello, Alberto Villarreal sugiere que la política cultural debería asumir una posición de dirección artística y no sólo administrativa, ya que el desarrollo de las teatralidades también se realiza desde la oficina ("El teatro como contrapeso" 93). Sobre esa directriz, la mirada crítica -al tanto de las condiciones de producción, lenguajes escénicos, objetivos y alcances de las propuestas- posee un gran potencial.

El Centro de Investigación y Documentación Dramática Norteatro asume con gusto y rigor la incidencia crítica sobre las puestas en escena. Durante los desmontajes, abrimos el diálogo no sólo con el público, sino con los teatristas, quienes aportaron su experiencia para vislumbrar el hecho escénico en su totalidad. Nuestras reseñas, además de guardar memoria de cada montaje, consideran el proceso creativo para reflexionar sobre lo que ocurrió en las tablas, en ese efímero momento en el que todos -gestores, creadores y espectadores- hacemos teatro.

\section{Fuentes consultadas}

Avendaño, Fernanda. "Nanas, cariños y apapachos". Norteatro, Centro de Investigación y Documentación Dramática Norteatro, 15 de agosto de 2018, www.norteatro.com/ wp/nanas-carinos-y-apapachos, consultado el 30 de agosto de 2018.

Balderas, Óscar. “"El Caimán», terror de trabajadoras sexuales en el DF”. El Universal, 23 de julio de 2013, http://archivo.eluniversal.com.mx/primera-plana/2013/impreso/ el-caiman-terror-de-trabajadoras-sexuales-en-el-df-42583.html, consultado el 30 de agosto de 2018.

Bujeiro, Verónica. "El teatro como contrapeso. Conversación con Alberto Villarreal”. Letras Libres, núm. 181, 2014, pp. 92-93.

Diéguez, lleana. "Des/tejer, desmontar, de/velar. (A modo de introducción)". Des/tejiendo escenas: desmontajes. Procesos de investigación y creación, compilado por Ileana Diéguez. Ciudad de México: Universidad Iberoamericana, 2009, pp. 9-20.

Goldfinger, Evelyn. “Theatre for Babies: A New Kind of Theatre?”. Key Concepts in Theatre/Drama, editado por Shifra Schonmann. Rotterdam: Sense Publishers, 2011, pp. 295-299. 
Ita, Fernando de. "El estado de las Muestras". Teatro en los estados 2007-2017, editado por Alejandra Serrano. Ciudad de México: Teatro Mexicano, 2018, p. 37.

Martínez, Yazmín. "Gritos en silencio". Norteatro, Centro de Investigación y Documentación Dramática Norteatro, 27 de septiembre de 2018, www.norteatro.com/wp/ gritos-en-silencio, consultado el 30 de noviembre de 2018.

Montiel, Carlos Urani. "Y ese es mi coraje". Norteatro, Centro de Investigación y Documentación Dramática Norteatro, 11 de agosto de 2018, www.norteatro.com/wp/y-esees-mi-coraje, consultado el 30 de agosto de 2018.

Montiel, Carlos Urani. "Público y expectación en El caimán y los sapos, de Edeberto Pilo Galindo". La puesta en escena y el espacio teatral, compilado por Roberto Ransom Carty y Raúl Valles. Ciudad de México: Ficticia, 2017, pp. 259-271.

Olmos de Ita, Enrique. "Once momentos destacados de la Muestra Nacional de Teatro 2017". Letras Libres, 18 de diciembre de 2017, www.letraslibres.com/mexico/arte/ once-momentos-destacados-la-muestra-nacional-teatro-2017, consultado el 30 de agosto de 2018.

Rubio, Antonio. "Tócala otra vez, Onésimo". Norteatro, Centro de Investigación y Documentación Dramática Norteatro, 19 de agosto de 2018, www.norteatro.com/wp/ tocala-otra-vez-onesimo, consultado el 30 de agosto de 2018.

Sanchis Sinisterra, José. Narraturgia: dramaturgia de textos narrativos. Ciudad de México: Paso de Gato, 2012.

Secretaría de Cultura del Estado de Jalisco. MET Jalisco 2018. Programa de mano. Gobierno del Estado: Guadalajara, 2018.

Serrano, Alejandra. "Revisar las bases de las MET, tarea pendiente". Teatro en los estados 2007-2017, editado por Alejandra Serrano. Ciudad de México: Teatro Mexicano, 2018, p. 37.

Apapacho, de Nataly Muñoz Proo. Dirigida por Nataly Muñoz Proo, Proyecto NIA, agosto de 2018, MET Chihuahua, Teatro Experimental Octavio Trías, Ciudad Juárez.

El caimán y los sapos, de Edeberto Galindo. Dirigida por Abraxas Trías ,1939 Teatro Norte, agosto de 2018, MEт Chihuahua, Teatro Víctor Hugo Rascón Banda, Ciudad Juárez.

La luz de las ausencias, de Saúl Enríquez. Dirigida por Saúl Enríquez, Teatro Bárbaro, agosto de 2018, MET Chihuahua, Teatro Experimental Octavio Trías, Ciudad Juárez.

Por favor cierra la puerta, gracias, creación colectiva. Dirigida por Damián Cervantes, Vaca 35 y Laboratorio Escénico Teatro de Fronteras, agosto de 2018, мEт Chihuahua, Espacio Alternativo Punta de Lanza, Ciudad Juárez. 